\title{
Applications of a modified Cortipac procedure for the estimation of urinary free cortisol in various clinical situations
}

\author{
PETER WEST \\ From the Department of Chemical Pathology, St George's Hospital, London SW17 OQT, UK
}

SUMmary A modification of the Cortipac procedure (Radiochemical Centre, Amersham) for the estimation of urinary free cortisol was found to be of value in the diagnosis of Cushing's syndrome and in the differentiation of simple obesity from that due to Cushing's syndrome. The effect of renal failure and late pregnancy on the urinary free cortisol was also studied. The results were expressed both in terms of the urinary free cortisol and as a urinary free cortisol:creatinine ratio.

The biological activity of cortisol is exerted by the non-protein bound fraction circulating in the blood, and it is this fraction that should ideally be measured in order to assess the adrenocortical status of a patient. The measurement of urinary free cortisol is stated to correlate well with changes in circulating unbound plasma cortisol.

The urinary free cortisol concentration can be measured with good specificity and accuracy by competitive protein binding assays (Beardwell et al., 1968; Burke and Beardwell, 1973).

Keenan (1975) described a modification of the Cortipac procedure (Radiochemical Centre, Amersham) for the measurement of cortisol in the urine, involving a preliminary extraction into dichloromethane, evaporation of the solvent, and uptake of the residue into plasma from a subject whose adrenal cortex had been suppressed with dexamethasone.

Wiener and Tan (1978) described a modified Cortipac procedure which eliminated the need for a dexamethasone-suppressed plasma. Their method involved extraction of cortisol from the urine into dichloromethane, followed by evaporation of the solvent under $\mathrm{N}_{2}$ at $55^{\circ} \mathrm{C}$. After uptake of the residue in water and transfer of an aliquot to a Cortipac test vial, the procedure was identical with that of the Radiochemical Centre, Amersham.

The purpose of the present study was to evaluate the method of Wiener and Tan (1978) in various

Received for publication 18 July 1979 clinical situations such as late pregnancy (Burke and Roulet, 1970), renal failure (Gilliland and Phillips, 1978), and obesity (Beardwell et al., 1968).

\section{Subjects studied}

Twenty-four-hour urine samples were received without preservative from each of the following groups of subjects:

CONTROL SUBJECTS

Twenty-one healthy laboratory staff, 12 men and 9 women aged 19 to 50 years carrying out their normal daily work.

LATE PREGNANCY

Sixteen normal female inpatients in the last trimester of pregnancy.

RENAL FAILURE

Seven patients with stable renal failure and creatinine clearances below $50 \mathrm{ml} / \mathrm{min}$.

\section{OBESITY}

A total of 17 urines were received from nine subjects not thought to have Cushing's syndrome on the evidence available. Urinary free cortisol was assayed once in two subjects, twice in six subjects, and on three occasions in one subject. All subjects were female, aged 19 to 50 (mean 31) years with a weight range of 111-147 (mean 133) kg. The percentage of the ideal body weight ranged from 200 to $280 \%$ (mean 245\%). 
CUSHING'S SYNDROME

Four patients with Cushing's syndrome diagnosed on both laboratory and clinical criteria.

Method

Approximately $3 \mathrm{ml}$ of each 24-hour sample was kept at $-20^{\circ} \mathrm{C}$ until analysis. Urinary free cortisol was estimated according to the procedure of Wiener and Tan (1978).

Urine samples were extracted singly into dichloromethane but duplicate volumes of the extract were then taken and set up at the evaporation stage for both standards and test samples. The difference between the duplicates was below $3 \%$ in all cases tested.

Within-batch and overall batch precision was tested at a low and high level of urinary free cortisol using two pooled urine samples stored at $-20^{\circ} \mathrm{C}$, one with a mean of $195 \mathrm{nmol} / 24 \mathrm{~h}$, the other with a mean of $780 \mathrm{nmol} / 24 \mathrm{~h}$. Within-batch and overall batch coefficients of variation were $5 \%$ and $9 \%$ respectively for the former, $6 \%$ and $8 \%$ for the latter.

Aqueous standards were prepared for each analysis from the stock cortisol solution kept at $4^{\circ} \mathrm{C}$. Fresh stock solution was prepared after two months, and an almost identical standard curve was obtained when compared with the earlier set of working standards, showing the stock solutions to be stable for at least two months at $4^{\circ} \mathrm{C}$.

The following steroids can interfere with the assay procedure: cortisone, 11 deoxycortisol, progesterone, prednisone, prednisolone, and corticosterone. The following are claimed to have no effect: dexamethasone, cholesterol, and oestriol.

Creatinine was estimated by the Jaffé reaction (Chasson et al., 1961) on the same 24-hour urine sample in the control and obesity subjects so that, in addition to expressing the results in terms of urinary free cortisol, results were also expressed as a urinary free cortisol:creatinine ratio.

\section{Results}

\section{CONTROL SUBJECTS}

Urinary free cortisol values in the control subjects gave a mean $\pm 1 \mathrm{SD}$ of $301 \pm 79 \mathrm{nmol} / 24 \mathrm{~h}$ and ranged from 160 to $462 \mathrm{nmol} / 24 \mathrm{~h}^{1}$ (Table 1). The distribution of values is shown in the Figure.

The urinary free cortisol:creatinine ratio gave a mean $\pm 1 \mathrm{SD}$ of $22.6 \pm 5.9 \mathrm{nmol} / \mathrm{mmol}$ creatinine, and values ranged from 14.8 to $34.6 \mathrm{nmol} / \mathrm{mmol}$ creatinine $^{1}$ (Table 1 ).

${ }^{1}$ Minimum and maximum values obtained.
Table 1 Urinary free cortisol and urinary free cortisol: creatinine ratio values in the control subjects

\begin{tabular}{lll}
\hline Subject & $\begin{array}{l}\text { Urinary free cortisol } \\
(\text { nmol/24 h) }\end{array}$ & $\begin{array}{l}\text { Urinary free cortisol: } \\
\text { creatinine ratio } \\
\text { (nmol/mmol creatinine) }\end{array}$ \\
\hline 1 & & $27 \cdot 8$ \\
2 & 353 & $32 \cdot 8$ \\
3 & 322 & $19 \cdot 0$ \\
4 & 241 & $16 \cdot 0$ \\
5 & 460 & $17 \cdot 0$ \\
6 & 284 & $19 \cdot 4$ \\
7 & 182 & $26 \cdot 1$ \\
8 & 341 & $22 \cdot 6$ \\
9 & 364 & $28 \cdot 4$ \\
10 & 160 & $30 \cdot 2$ \\
11 & 462 & $15 \cdot 0$ \\
12 & 286 & $23 \cdot 7$ \\
13 & 284 & $17 \cdot 4$ \\
14 & 291 & $34 \cdot 6$ \\
15 & 294 & $14 \cdot 8$ \\
16 & 331 & $19 \cdot 1$ \\
17 & 210 & $19 \cdot 2$ \\
18 & 350 & $30 \cdot 0$ \\
19 & 391 & $22 \cdot 3$ \\
20 & 247 & $18 \cdot 7$ \\
21 & 264 & $20 \cdot 2$ \\
& 214 & $22 \cdot 6$ \\
Mean & 301 & $5 \cdot 9$ \\
\hline 1 & 79 & \\
\hline & &
\end{tabular}

\section{LATE PREGNANCY}

The urinary free cortisol for the 16 subjects gave a mean \pm 1 SD of $809 \pm 198 \mathrm{nmol} / 24 \mathrm{~h}$. The distribution of values is shown in the Figure. In 15 of the 16 subjects $(94 \%)$, the level of urinary free cortisol ranged from 546 to $1240 \mathrm{nmol} / 24 \mathrm{~h}^{1}$. In the 16 th subject, the value was at the upper end of the control group range (433 $\mathrm{nmol} / 24 \mathrm{~h})$.

RENAL FAILURE

Urinary free cortisol values gave a mean \pm 1 SD of $73 \pm 36 \mathrm{nmol} / 24 \mathrm{~h}$ and ranged from 7 to $134 \mathrm{nmol} /$ $24 \mathrm{~h}^{1}$. Urines were received from several other subjects with reduced creatinine clearances (below $50 \mathrm{ml} / \mathrm{min}$ ). These subjects were found to have normal or elevated urinary free cortisol levels. Their results were attributed to the stressful nature of their respective illnesses. Stress is an important factor which can lead to an elevated level of cortisol.

\section{OBESITY}

Urinary free cortisol in eight of the nine subjects gave a mean \pm 1 SD of $277 \pm 61 \mathrm{nmol} / 24 \mathrm{~h}$ and values ranged from 171 to $375 \mathrm{nmol} / 24 \mathrm{~h}$ (Table 2). The ninth subject had an elevated level (545 nmol/24 h). She was not taking any drug known to affect the urinary free cortisol measurement. A plasma cortisol measured at an earlier date was at the upper end of the normal range. The high value 


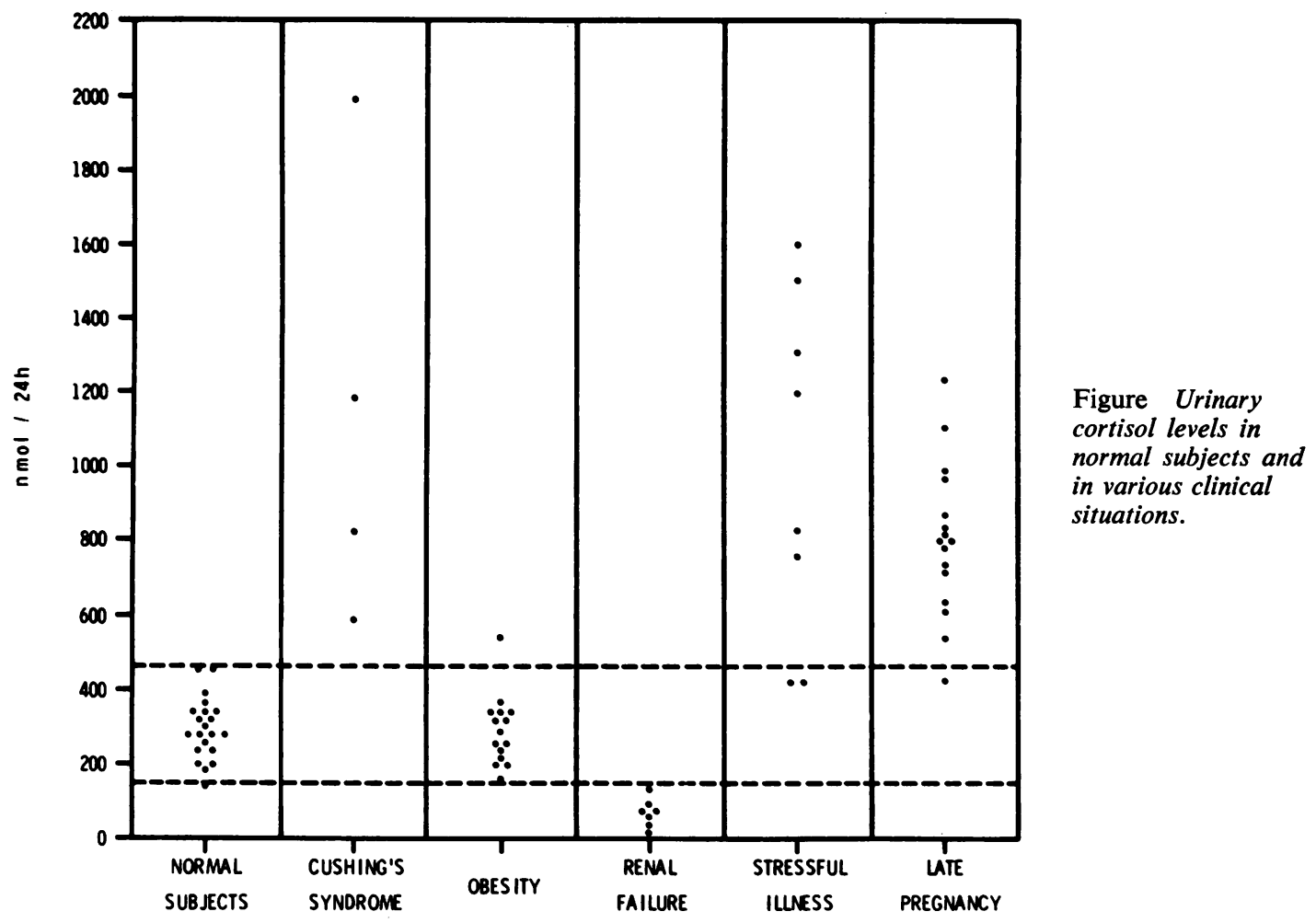

Table 2 Urinary free cortisol and urinary free cortisol: creatinine ratio values in the obese subjects

\begin{tabular}{lll}
\hline Subject & $\begin{array}{l}\text { Urinary free cortisol } \\
(\text { nmol/24 } h)\end{array}$ & $\begin{array}{l}\text { Urinary free cortisol: } \\
\text { creatinine ratio } \\
(\text { nmol/mmol creatinine })\end{array}$ \\
\hline 1 & 290 & $19 \cdot 3$ \\
& 205 & $18 \cdot 1$ \\
2 & 213 & $23 \cdot 5$ \\
& 322 & $19 \cdot 8$ \\
3 & 220 & $16 \cdot 5$ \\
& 330 & $18 \cdot 0$ \\
4 & 375 & $19 \cdot 0$ \\
& 260 & $28 \cdot 9$ \\
5 & 275 & $29 \cdot 7$ \\
6 & $545^{*}$ & $40 \cdot 4 *$ \\
6 & 330 & $20 \cdot 8$ \\
7 & 321 & $16 \cdot 3$ \\
& 236 & $15 \cdot 8$ \\
8 & 201 & - \\
9 & 171 & $17 \cdot 6$ \\
9 & 336 & $19 \cdot 0$ \\
& 347 & $22 \cdot 0$ \\
Mean & 277 & $20 \cdot 4$ \\
SD & 61 & $4 \cdot 2$ \\
\hline
\end{tabular}

* Subject 5 was excluded from the calculation of the mean and standard deviation. cannot at present be explained. The distribution of values for all nine subjects is shown in the Figure.

As for the control group, results were also expressed in terms of urinary free cortisol:creatinine ratio. Eight of the nine subjects had values within the range of the control group (mean \pm 1 SD being $20.4 \pm 4 \cdot 2 \mathrm{nmol} / \mathrm{mmol}$ creatinine) (Table 2). The ninth subject, who had an elevated urinary free cortisol, also had an elevated urinary free cortisol: creatinine ratio.

\section{CUSHING'S SYNDROME}

Four patients with Cushing's syndrome had urinary free cortisol values that were elevated. The mean value was $1149 \mathrm{nmol} / 24 \mathrm{~h}$, values ranging from 586 to $2000 \mathrm{nmol} / 24 \mathrm{~h}$.

Dexamethasone (0.5 mg six-hourly after a loading dose of $4 \mathrm{mg}$ ) was given to one subject and caused a reduction of the urinary free cortisol from 1183 to $400 \mathrm{nmol} / 24 \mathrm{~h}$ after 24 hours.

\section{Discussion}

The modified Cortipac procedure of Wiener and Tan (1978) was studied in various clinical situations. The findings of Burke and Roulet (1970) that levels of urinary free cortisol are elevated in late pregnaiıcy 
were confirmed in this study. Gilliland and Phillips (1978) reported reduced levels of urinary free cortisol in patients with impaired renal function and advised against using this test in such cases. Their findings were confirmed in the present study. Beardwell et al. (1968) reported normal levels of urinary free cortisol in their obese subjects. In the present study, eight of the nine subjects had normal levels for both the urinary free cortisol and the urinary free cortisol:creatinine ratio.

In the four subjects with Cushing's syndrome, the level of urinary free cortisol was elevated.

Measurement of urinary free cortisol is a means of diagnosing Cushing's syndrome but is of less value in the presence of impaired renal function or in subjects in late pregnancy. The present study confirms the value of the test in differentiating between subjects with obesity and those with Cushing's syndrome.

I thank Dr P. Kopelman, of the Department of Physiology, St George's Hospital, for the provision of the samples from the obese subjects, and Professor J. A. Owen and Dr G. E. Levin, of the Department of Chemical Pathology, St George's Hospital, for useful advice.

\section{References}

Beardwell, C. G., Burke, C. W., and Cope, G. L. (1968). Urinary free cortisol measured by competitive protein binding. Journal of Endocrinology, 42, 79-89.

Burke, C. W., and Beardwell, C. G. (1973). Cushing's syndrome: an evaluation of the clinical usefulness of urinary free cortisol and other urinary steroid measurements in diagnosis. Quarterly Journal of Medicine, 42, 175-204.

Burke, C. W., and Roulet, F. (1970). Increased exposure of tissues to cortisol in late pregnancy. British Medical Journal, 1, 657-659.

Chasson, A. L., Grady, H. J., and Stanley, M. A. (1961). Determination of creatinine by means of automatic chemical analysis. American Journal of Clinical Pathology, 35, 83-88.

Gilliland, J., and Phillips, P. J. (1978). Urinary free corticosteroid excretion and renal function. Journal of Clinical Pathology, 31, 671-672.

Keenan, J. (1975). Measurement of urinary free cortisol with a Cortipac modified extraction procedure. Technical Bulletins, Radiochemical Centre, Amersham, $75 / 9$.

Wiener, K., and Tan, B. H. A. (1978). A modification of the Cortipac procedure for the estimation of urine free cortisol. Annals of Clinical Biochemistry, 15, 115-116.

Requests for reprints to: Mr P West, Department of Chemical Pathology, St George's Hospital Medical School, Cranmer Terrace, London SW17 0QT, UK. 